\title{
CASE REPORT - ACUPUNCTURE TREATMENT IN FEMALE PATIENTS WITH ELEVATED ANTI-TPO LEVELS
}

\author{
Blagica Arsovska 1,2凹, Jihe Zhu 1, Kristina Kozovska 1, 3 \\ ${ }^{1}$ Faculty of Medical Sciences, University Goce Delchev, Shtip, Republic of Macedonia \\ ${ }^{2}$ Institute of Biology, Faculty of Natural Sciences and Mathematics, Skopje, Republic of Macedonia \\ ${ }^{3}$ Medicine Faculty, St. Cyril and Methodius University of Skopje, Republic of Macedonia
}

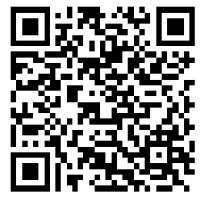

DOI: https://doi.org/10.29121/granthaalayah.v8.i12.2020.2520

\section{Article Type: Case Report}

Article Citation: Blagica Arsovska, Jihe Zhu, and Kristina Kozovska. (2020). CASE REPORT ACUPUNCTURE TREATMENT IN FEMALE PATIENTS WITH ELEVATED ANTI-TPO LEVELS. International Journal of Research GRANTHAALAYAH, 8(12), 1-4. https://doi.org/10.29121/granthaa layah.v8.i12.2020.2520

Received Date: 23 November 2020

Accepted Date: 21 December 2020

Keywords:

Traditional Chinese Medicine

Acupuncture

Thyroid

Hashimoto's

\section{ABSTRACT}

Slightly elevated level of TSH, normal T3/T4 levels and high Anti TPO level is a sign of subclinical hypothyroidism. More than $90 \%$ of the thyroid disease cases are caused by diseases that are autoimmune in nature. Hashimoto's thyroiditis is a progressive and lifelong autoimmune disease. It starts subtly, usually long before the patient is diagnosed and develops slowly. In this research is presented a case of 38-year-old woman with elevated anti-TPO levels, without previous thyroid disorders. The patient has done 10 acupuncture treatments every two weeks in a period of 6 months. Before the treatment the anti-TPO level was $91.2 \mathrm{U} / \mathrm{ml}(<60.0$ $\mathrm{U} / \mathrm{ml}$ ). After the treatment it was normalized to $54.8 \mathrm{U} / \mathrm{ml}$. The TSH level before the treatment was also slightly elevated to the upper range -4.39 $\mathrm{pIU} / \mathrm{ml}(0.55-4.75 \mathrm{pIU} / \mathrm{ml})$. After the treatment it was normalized to 2.08 $\mathrm{pIU} / \mathrm{ml}$. Acupuncture points used in the treatment are: RN4 (QuanYuan), RN6 (QiHai), DU20 (BaiHui), GB20 (FengChi), DU14 (DaZhui), LI4 (HeGu), DU4 (MingMen), BL15 (XinShu), ST9 (RenYing), BL20 (PiShu), BL23 (ShenShu), LR2 (TaiChong), SP9 (YinLingQuan), SP6 (SanYinJiao), ST36 (ZuSanLi), KI3 (TaiXi) and Ashi (trigger) points located on the neck (front and back). The acupuncture treatment is always most effective at the onset of the disease and gives good results in such pre-conditions. The acupuncture treatment is a great choice for prevention, as well as for more serious and advanced conditions.

\section{INTRODUCTION}

Slightly elevated level of TSH, normal T3/T4 levels and high Anti TPO level is a sign of subclinical hypothyroidism. Subclinical hypothyroidism represents an early and mild form of hypothyroidism, where the body doesn't produce enough thyroid hormones. The condition is called subclinical because only the serum level of thyroid-stimulating hormone (TSH) is a little bit above the normal. The thyroid hormones (T3 and T4) are still within the laboratory's normal range. Positive anti-TPO confirms that the cause of the condition is autoimmune, meaning that these antibodies in the body (which act against the thyroid cells), lead to hypothyroidism. The condition is most often progressive.[1]

More than $90 \%$ of the thyroid disease cases are caused by diseases that are autoimmune in nature. Hashimoto's thyroiditis is a progressive and lifelong autoimmune disease. It starts subtly, usually long before the patient is diagnosed and develops slowly.[2][3][4]

(C) 2020 The Author(s). This is an open access article distributed under the terms of the Creative Commons Attribution License, which permits unrestricted use, distribution, and reproduction in any medium, provided the original author and source are credited. 
Common symptoms of hypothyroidism are: fatigue, depression, hair loss, weight gain, intolerance to cold, goiter, constipation and other. Some studies have shown that patients with hypothyroidism are twice at risk more likely to develop some heart diseases like high cholesterol and high blood pressure. [1]

Mainly, there are 5 stages of Hashimoto's disease:

- Stage 1 - Genetic predisposition - there is just a genetic predisposition, without any manifestations or changes in the thyroid hormones.

- Stage 2 - Immune Cell Infiltration of the Thyroid Gland - 90\% of the patients have elevated thyroid antibodies and normal thyroid hormones levels in this stage. Some symptoms like anxiety, mood swings, fatigue may be experienced. Sadly, lot of patients are not diagnosed for hypothyroidism in this stage, but are told to have 'mood symptoms. This is the ideal stage to start preventive precautions and prevent the progression of the disease.

- Stage 3 - Subclinical hypothyroidism - In this stage T3/T4 levels are normal and the TSH level is slightly elevated (3-10 mU/L).

- Stage 4 - Overt hypothyroidism - In this stage the TSH level is elevated and fT3/fT4 levels are low. This is usually the stage when the patients are diagnosed and start taking medications.

- Stage 5 - Progression to Other Autoimmune Disorders - In this stage the patient may develop another autoimmune disorder like celiac disease, multiple sclerosis, lupus, rheumatoid arthritis and other. The immune system is imbalanced and the patient may have enlarged thyroid and develop goiter, nodules or thyroid cancer.[4]

The conditions should not be approached the conventional way focusing only on one particular organ, instead the body should be treated as an integrated whole. Autoimmune conditions can be reversed.[5]

Hypothyroidism is effectively treated with Traditional Chinese Medicine (TCM) for many years. The condition arises due to chronic deficiency of one or more vital substances of the body: Blood, Qi, Yin, Yang and Essence. The disease may start with general Qi deficiency and then progress and affect all organ systems over the time. Three primary involved organs in the pathogenesis of hypothyroidism are: Spleen, Kidney and Heart. Other organs that may be affected are Lungs and Liver, but in an indirect manner. The initial stage of the condition is equivalent to subclinical hypothyroidism and there are mainly present symptoms of Spleen Qi deficiency. [6]

\section{CASE REPORT}

In this research is presented a case of 38-year-old woman with elevated anti-TPO levels, without previous thyroid disorders. No medication was taken before, during and after the acupuncture treatment. The patient was feeling fatigue and palpitations, especially during the night.

The patient has done 10 acupuncture treatments every two weeks in a period of 6 months. The treatments were done in a clinic for acupuncture and TCM in Skopje, Macedonia by a doctor specialist in acupuncture. Treatments were indoor, with duration of 30-45 minutes each side of the body. In the treatment were used fine sterile disposable needles sized $0.25 \times 25 \mathrm{~mm}$ manufactured by Wuijuiang City Medical \& Health Material Co., LTD.

Acupuncture points used in the treatment are: RN4 (QuanYuan), RN6 (QiHai), DU20 (BaiHui), GB20 (FengChi), DU14 (DaZhui), LI4 (HeGu), DU4 (MingMen), BL15 (XinShu), ST9 (RenYing), BL20 (PiShu), BL23 (ShenShu), LR2 (TaiChong), SP9 (YinLingQuan), SP6 (SanYinJiao), ST36 (ZuSanLi), KI3 (TaiXi) and Ashi (trigger) points located on the neck (front and back).

On table 1 are shown the blood test results done before and after the acupuncture treatments. Before the treatment the anti-TPO level was $91.2 \mathrm{U} / \mathrm{ml}(<60.0 \mathrm{U} / \mathrm{ml})$. After the treatment it was normalized to $54.8 \mathrm{U} / \mathrm{ml}$. The TSH level before the treatment was also slightly elevated to the upper range $-4.39 \mathrm{pIU} / \mathrm{ml}(0.55-4.75 \mathrm{pIU} / \mathrm{ml})$. After the treatment it was normalized to $2.08 \mathrm{pIU} / \mathrm{ml}$. the FT4 level was in a normal range before and after the treatment.

Table 1: Blood test results done before and after the treatment

\begin{tabular}{|c|c|c|c|}
\hline & TSH $(0.55-4.75 \mathrm{pIU} / \mathrm{ml})$ & FT4 $(0.89-1.76 \mathrm{ng} / \mathrm{dl})$ & Anti-TPO $(<60.0 \mathrm{U} / \mathrm{ml})$ \\
\hline Before treatment & $4.39 \mathrm{pIU} / \mathrm{ml}$ & $1.03 \mathrm{ng} / \mathrm{dl}$ & $91.2 \mathrm{U} / \mathrm{ml}$ \\
\hline After treatment & $2.08 \mathrm{pIU} / \mathrm{ml}$ & $1.01 \mathrm{ng} / \mathrm{dl}$ & $54.8 \mathrm{U} / \mathrm{ml}$ \\
\hline
\end{tabular}

International Journal of Research -GRANTHAALAYAH 
This stage could be explained as subclinical hypothyroidism. This is a stage where the TSH blood tests won't be sensitive enough to reveal Hashimoto's, levels won't be much elevated, but the patient will test positive for thyroid antibodies (TPO or TG). In this stage, an increase in TSH levels can increase the inflammation of the thyroid gland too.

For an autoimmune disease to develop, three things must be present:

1) A genetic predisposition

2) Intestinal permeability

3) Triggers

In this stage it is possible to reverse the condition without using medications. It is very important to find the root cause of the disease. Every patient has a different root cause, as everyone has own unique genes and lifestyle. Possible triggers are: stress, toxins, food sensitivities, infections and other. However, thyroid hormone replacement medication won't help and address the root cause of the disease. [4] [5]

The aim of the acupuncture treatment is to help the body naturally balance the immune system on its own, without using any additional medications. The goal is to balance the Qi energy in the affected organs - Spleen and Kidney, revitalize the stagnated energy, tonify the organs, warm the Kidney Yang and eliminate excessive dampness and phlegm if present[7][8]

\section{CONCLUSION}

The acupuncture treatment is always most effective at the onset of the disease and gives good results in such early-stage conditions. The acupuncture treatment is a great choice for prevention, as well as for more serious and advanced conditions.

\section{SOURCES OF FUNDING}

This research received no specific grant from any funding agency in the public, commercial, or not-for-profit sectors.

\section{CONFLICT OF INTEREST}

The author have declared that no competing interests exist.

\section{ACKNOWLEDGMENT}

None.

\section{REFERENCES}

[1] Christiano D; What Is Subclinical Hypothyroidism? 2020 [www.healthline.com]

[2] Arsovska B, Zhu J, Kozovska K; CASE REPORT - ACUPUNCTURE TREATMENT IN FEMALE PATIENT PRESENTED WITH PRIMARY HYPOTHYROIDISM. International Journal of Research -GRANTHAALAYAH, 8(6), 71-74. 2020

[3] Dumont JE, et al; Physiological and pathological regulation of thyroid cell proliferation and differentiation by thyrotropin and other factors, 1992

[4] Wentz I; The 5 Stages of Hashimoto's Thyroiditis; 2020 [www.thyroidpharmacist.com]

[5] Wentz I; Why Hashimoto's Requires a Root Cause Approach; 2019 [www.thyroidpharmacist.com]

[6] Malikov D; Traditional Chinese Medicine Approach to Hypothyroidism. Int J Complement Alt Med 5(1): 00142; 2017

[7] Cohen C; TCM Treatment Principles for Hashimoto's Thyroiditis (with Case Study); 2019 [www.acuproacademy.com] 
Case Report - Acupuncture Treatment in Female Patients with Elevated Anti-TPO Levels

[8] Arsovska B, Zhu J, Kozovska K; Case Report - Acupuncture treatment in male patient with Hashimoto thyroiditis; International Journal of Research - Granthaalayah, 7(9), 288-291.; 2019. 